\title{
EXAMINING THE EFFECTS OF THREE JIGSAW LISTENING ACTIVITIES ON TEXT COMPREHENSION: AN EXPLORATORY STUDY
}

\author{
Nguyen Chi Duc*, Pham Xuan Tho \\ VNU University of Languages and International Studies \\ Pham Van Dong, Cau Giay, Hanoi, Vietnam \\ Received 14 October 2019 \\ Revised 19 December 2019; Accepted 22 December 2019
}

\begin{abstract}
This exploratory study examined the relative effects on L2 listening comprehension of three different jigsaw procedures: having learners listen to either the first or the second half of an input text and then share the content with a classmate who did not listen to the same half (Jigsaw-Listening 1), or having them implement the same procedure as above, but followed by their actual exposure to either the remaining content (Jigsaw-Listening 2) or the whole listening passage (Jigsaw-Listening 3). Their text comprehension as gauged by ten multiple-choice content questions was subsequently compared to that obtained by learners who listened to the same complete input text, either once (One-time Listening) or twice (Repeated-Listening). The quantitative results showed that all Jigsaw Listening groups obtained better text comprehension than the Onetime Listening group. The learners in Jigsaw-Listening 2 and 3 were also found to outperform those in the Repeated-Listening group. Follow-up interviews with some participants randomly selected from the JigsawListening groups revealed that these learners carried out different metacognitive strategies to complete their assigned listening procedures and the more strategies they used, the better listening outcome they produced. These findings have implications for both L2 listening instructors and course designers.
\end{abstract}

Keywords: jigsaw listening, text comprehension, metacognitive listening strategies, advance organizers

\section{Introduction}

The idea of jigsaw listening dates back to the 1970s (e.g., Geddes and Sturtridge, 1978). In this listening procedure, an input text is often divided into smaller sections, which are subsequently assigned as a listening task to different groups of L2 learners. After the first round of listening, learners are regrouped to share the content with those who have not listened to the same section yet. In some

\footnotetext{
* Corresponding author: Tel.: 84-346816302

Email: ducnc@vnu.edu.vn
}

cases, learners are also provided with the opportunity to actually listen to the section of the listening text that their classmates have told them about or to the whole listening text. Jigsaw listening was first introduced into the language classroom mainly as a tool to promote learner autonomy and cooperative learning (see Harlim (1999) for a detailed review). However, this classroom activity may be beneficial for text comprehension (for reasons discussed further below).

Effects of jigsaw activities on text comprehension have been relatively wellresearched in the context of L2 reading, but 
are surprisingly under-researched in the context of L2 listening. Such research would be welcome for at least three reasons. First and foremost, it may provide instructors of L2 listening courses with evidence regarding whether jigsaw listening has merits other than fostering learner autonomy and cooperative learning. As jigsaw listening often takes up more classroom time due to the presence of the sharing/speaking session inserted in between, this evidence allows us to justify whether our investment of such extra time is worthwhile. Second, it can help answer the question as to whether different jigsaw activities have the same or differing effects on L2 listening comprehension, which, in turn, may inform decision making upon what types of jigsaw activities should be incorporated in our listening-based lessons. Finally, it also gives us initial ideas about what types of metacognitive processes L2 learners may use during jigsaw listening and how these processes influence the listening outcome.

\section{Literature Review}

\section{Jigsaw activities and $L 2$ reading and listening ability development}

Most previous research on the effects of jigsaw activities concerns the development of L2 reading ability. Using a between-participant research design, these studies compared the degrees of L2 reading ability development between a jigsaw reading condition and a control condition (where no jigsaw reading was applied). Their results consistently show that jigsaw activities brought about significantly better L2 reading ability than traditional instructional techniques (Prom, 2014; Kazemi, 2012; Mauludi, 2011). It should also be noted that such an effect might differ across different reading subskills. Prom (2012), for example, found that jigsaw reading could enhance L2 learners' skimming and inference skills to a great extent, but its effect on their scanning and fact-vs.-opinion differentiation skills was relatively small. Nevertheless, it is still clear from the above studies that jigsaw activities indeed foster the development of L2 reading ability. Such a positive effect is often attributed to the following factors. First, as jigsaw reading often requires L2 learners to read only a section of an input text, they can focus their mental resources on this section and apply different metacognitive strategies to facilitate their reading comprehension (Mauludi, 2011). Additionally, in jigsaw reading, learners need to share reading content with a classmate who has not been exposed to the same content yet. The announcement of such a sharing task at the pre-reading stage is likely to prompt learners to get more engaged in their reading process (Kazemi, 2012; Mauludi, 2011). Finally, the positive classroom atmosphere that jigsaw reading often brings about is also deemed to be conducive to learning (Kazemi, 2012). Taken altogether, jigsaw reading provides L2 readers with both cognitive and affective benefits.

Given the considerable amount of research investigating the effects of jigsaw activities on L2 reading ability development as already reviewed above, one might expect to see a similar number of such studies in the context of L2 listening. However, it appears that only two published experimental studies are available. One was carried out by Tuanany and Bharati (2017). In this study, EFL learners were involved either in a jigsaw listening or a problem-solving listening procedure (the nature of these procedures is not described). The effects of these listening procedures on L2 listening comprehension were determined by pre- and post-tests (neither is the nature of these tests described). The results showed that learners in both conditions significantly improved their scores from the pre-test to the post-test, but jigsaw listening was found to fare better than problem-solving listening. The effects of these listening techniques were both moderated by the level of the learners' listening anxiety. This study is limited in the regard that it did not compare the pre-test scores between the two treatment groups. As 
a consequence, the difference in their posttest scores might have been due to different listening abilities prior to this experiment.

The other study was conducted by Chofifah and Kumalarini (2013). In this study, a group of Grade $10^{\text {th }}$ EFL learners were first required to listen to a set of input materials and then completed a text comprehension test (which was used as a pre-test). In the experimental stage, they were split into different groups of five or six, listened to different parts of the materials above, got regrouped to report their listening content to those who were not exposed to the same parts yet, and then came back to their original groups for a wholeclass checking of their text comprehension. After the experiment, they were asked to listen to the entire input set again and completed the same text comprehension test (which was, in fact, used as a post-test in this study). The results showed that there was a significant improvement in their text comprehension scores from the pre-test to the post-test. This study also has several methodological limitations. The difference in the scores between the pre-test and the posttest could be attributed to the difference in the listening outcome after the first (i.e., in the case of the pre-test) and after the third listening to the same input (i.e., in the case of the post-test), regardless of the precise activities performed. The absence of a control/ comparison group makes it impossible to attribute this improvement to the nature of the treatment as such. Moreover, it can be argued that the procedure used in this study does not qualify as jigsaw listening as the learners were exposed to the complete input materials before they were asked to share information (and so there was no genuine information gap).

In sum, there is substantial evidence to suggest that jigsaw activities benefit L2 reading, but there is insufficient evidence to confirm that this also holds true for L2 listening. In addition, there has been, to the best of my knowledge, no empirical research that gives a closer look at the metacognitive processes that L2 learners engage in to complete jigsaw listening and the effects of these processes on their listening outcome. Thus, the present study aims to extend this research line.

Jigsaw listening and its potential benefits for text comprehension

As already suggested in the introduction, jigsaw listening may benefit L2 listening ability beyond fostering learner autonomy and cooperative learning. In what follows, I will discuss these benefits in more detail.

First of all, in jigsaw listening, learners are often required to share listening content with a classmate who has not been exposed to the same input material yet. Such a retelling activity might prompt learners to reprocess perceived information at a deeper level, which therefore enhances their understanding and retention of that content. Theoretically, this view is in line with Wittrock's Model of Generative Teaching of Comprehension (2010). In this model, Wittrock suggests that when learners are required to read/listen to an input text and then summarize the input content, they need to generate mental links between different ideas in that input material as well as between these ideas and relevant schemata in their long-term memory (my emphasis). This generation, in turn, helps them to cultivate greater comprehension and retention of that content. Previous research also supports this stance. Nguyen and Boers (2019), for example, carried out a classroom-based study to compare the effect on L2 listening comprehension of inserting a retelling activity into a cycle of repeated listening with that of mere repeated listening. The former indeed fared better. Another plausible explanation for this finding is that the retelling activity might have helped learners to identify what they missed in the first listening and therefore could have prompted them to collect this information in the second round of listening. 
In case learners are allowed to actually listen to the content that their classmates have just told them, what they receive from their classmates can work as an "advance organizer" of the upcoming listening content (Ausubel, 1978). This advance organizer is often found to facilitate L2 listening comprehension. Herron, Cole, York, and Linden (1995), for instance, compared L2 listening comprehension across three groups of learners. Two groups received either a summary of the video or multiple-choice questions about its content before watching it, while the third group received no such advance organizers. The former two groups subsequently scored significantly higher on a text comprehension test than the latter. Jafari and Hashim (2012) also compared the level of L2 listening comprehension across three different learning conditions. In this study, learners were required to listen to short passages, but received either a summary of the input content, a set of key words in those input materials or no support before listening. The results showed that the learners who received the key vocabulary or the summary of the input content before listening significantly outperformed those who did not receive any pre-listening support on a post-listening test. The effects on text comprehension of the summary and the key vocabulary condition were roughly the same. Follow-up interviews with the learners, however, revealed that they preferred receiving the summary to the key words. This was because the summary helped them to grasp the topic and the main ideas of the upcoming listening content, which, in turn, facilitated their input processing. Meanwhile, they considered the key words useless and even distractive to their listening process. These two studies clearly demonstrate a positive effect on L2 listening comprehension of giving learners a summary of input content as an advance organizer before they actually listen to an input text. There are two plausible explanations for this finding. First, such an advance organizer prompts learners to activate their top-down processing. In addition, it also helps reduce the amount of mental resources that they otherwise need for processing the input. This amount of mental resources can be reallocated for their bottom-up processing and also to help them move back and forth between top-down and bottom-up processes. Put differently, the summary above allows learners to make full use of both top-down and bottom-up processing - two crucial components of the listening process.

From the perspectives of metacognitive strategy training, the sharing session of jigsaw listening has two other potential benefits for L2 listening comprehension. On the part of summary providers, this session prompts them to re-examine the quality of their first listening. In case they are provided with the opportunity to listen to the input text a second time, they can recollect the information that they miss during their first listening. On the part of summary receivers, they may use the given topic, key ideas and idea organization as a basis to activate relevant schemata of topical knowledge (i.e., content schemata) and discourse structure (i.e., formal schemata) in their long-term memory and thus facilitate their top-down processing. Put differently, jigsaw listening may help learners to plan for, monitor their listening process, identify listening problems and find suitable solutions for these problems as well as evaluate their listening outcome - the four main metacognitive processes in Vandergrift and Goh's Model of Metacognitive Listening (2012). Previous research often shows that learners who are able to make full use of these four metacognitive processes are likely to succeed in their L2 listening. Gu, Hu and Zhang (2009), for instance, used verbal protocols to examine differences in listening strategies carried out by good and bad listeners. The results showed that the former consciously employed their previous topical and linguistic knowledge to reconstruct, interpret and summarize listening content as well as continually making predictions and/ 
or inferences about this content. By contrast, the latter spent most of their time decoding the input text rather than monitoring their listening processes. Vandergrift (2003) also compared the types of metacognitive processes employed by strong and weak L2 listeners. It was found that the former carried out planning, monitoring and problem-solving strategies to foster their listening process more frequently than the latter. Thus, a common recommendation derived from previous research is that such metacognitive strategies should be incorporated into listening-based lessons in some way.

Taken altogether, jigsaw listening is likely to prompt L2 learners to activate the metacognitive processes that are deemed to foster their interpretation and retention of input content. Thus, it is meaningful to investigate the effects on text comprehension of this listening procedure, especially the metacognitive processes that L2 learners employ as they perform it.

\section{The present study}

\section{Research aims and research questions}

This exploratory study investigates the relative effects on L2 listening comprehension of three different jigsaw listening activities: having learners listen to either the first half or the second half of an input text and then share the content with a classmate who has not listened to the same input material yet (a) or having them carry out the same procedure as above, but followed by their actual exposure to either the remaining half (b) or the whole listening passage (c). Their text comprehension is subsequently compared to that obtained by two comparison groups who listen to the same input text, but either once or twice. As we can see, the amount of time invested in each learning condition differs from one to another. Thus, the present study also examines whether the effects on L2 listening comprehension of those learning conditions (if any) are moderated by the amount of time on task as well. Finally, it takes a closer look at the metacognitive processes that L2 learners use to complete their assigned jigsaw listening activity and the effects of those processes on their listening outcome. Put differently, this study seeks to answer the following research questions:

a. Is better L2 listening comprehension obtained in the jigsaw listening groups than in the comparison groups?

b. If so, are the differences attributable simply to the differing amounts of time on task?

c. What metacognitive processes do learners use to carry out their assigned jigsaw listening task and how do these processes affect their listening outcome?

\section{Research participants}

Participants in this study were five groups of Vietnamese students of English as a foreign language (total $\mathrm{N}=178 ; 7$ males and 171 females). They were all aged 19 or 20 and enrolled in an intensive two-year language training program in order to improve their language proficiency to CEFR $\mathrm{C} 1$ level or IELTS overall band score of 6.5 (i.e., upper intermediate level). It should also be noted that these learners had all experienced jigsaw listening several times prior to this experiment. As all data were normally distributed, a oneway ANOVA test for independent samples was implemented to compare their pre-treatment listening abilities (which were based on their latest official listening test scores) across all groups. No difference was found: $F(4,173)=$ $0.83(p=.51)$. This means that these groups had a roughly equal listening ability before they were involved in this experiment. Thus, any difference in their listening outcomes can be attributed to the effects of their learning conditions.

Study material and dependent measure 
At the time of data collection for this study, the participants were learning academic English in order to enrol in BA courses in which English is used as a medium of instruction. Thus, it was ecologically valid to use an academic listening text as study material in the present experiment. Four passages taken from the past IELTS listening tests (i.e., two tutorial sessions and two minilectures) were first selected as the potential input texts. A group of 16 EFL learners who had the same L2 proficiency level as those who were recruited for this study were invited to rate the selected listening passages with regards to their comprehensibility and general appeal. Based on their feedback, a sevenminute tutorial session between a university tutor and two Literature-majored students

\section{What is the tutorial mainly about?}

Key contents in the Literature course Storyline of the Secret Garden novel Learning points from Secret Garden

In the scoring procedure, the participants of this study were awarded 1 and 0 points for correct and incorrect responses, respectively. Using the actual scores, the internal consistency of the test was computed by a means of splithalf reliability check. The Pearson correlation coefficient between the scores taken from the two halves of the test (i.e., the odd- and the even-numbered test items) was .87 , indicating the test was consistent in the way it measured the target ability.

\section{Procedure of data collection and data analysis}

The five intact classes were randomly assigned to one of the three jigsaw conditions or one of the two comparison conditions. In one jigsaw condition, learners were required to listen to either the first or the second half of the study material and then share the content in the target language with a classmate who had not listened to the same half $(n=36)$. In the second jigsaw condition, was chosen (the link to this material is given in Appendix A). According to their scores on Schmitt, Schmitt and Clapham's (2001) Vocabulary Levels Test, the participants in this study had receptive knowledge of the most frequent 5,000 word families in English. With this amount of lexical knowledge, they were estimated to know $98.70 \%$ of all running words in the chosen text. A lexical 'coverage' of $98 \%$ is generally believed to be a prerequisite for an adequate understanding of both general and academic English texts (van Zeeland and Schmitt, 2013).

The dependent measure of the present study was a set of ten multiple-choice content questions which focused on both global and local understanding. Below are two examples of such questions:

7. In the novel, whom do roses symbolize?

$$
\begin{aligned}
& \text { Mary Lennox } \\
& \text { Colin Craven } \\
& \text { Mistress Craven }
\end{aligned}
$$

learners carried out the same procedure as above, but they were subsequently asked to listen to the half of the recording which their peer had told them about $(n=36)$. In the third jigsaw condition, learners also followed the same procedure as in the first, but they were subsequently asked to listen to the whole listening passage, i.e., the part they had already listened to once before and the part which their peer had told them about $(n=36)$. In the two comparison conditions ( $n=35$ in both cases), learners listened to the same text, but either once or twice. Henceforth, these conditions are referred to as Jigsaw Listening 1, Jigsaw Listening 2, Jigsaw Listening 3, One-time Listening and Repeated Listening, respectively. Inevitably, the amount of time invested in each learning condition differed. Specifically, this amount of time was 6.16 minutes in the One-time Listening condition, 12.32 minutes in the 
Repeated Listening condition, 8.16 minutes in the Jigsaw Listening 1 condition, 11.16 minutes in the Jigsaw Listening 2 condition, and 14.32 minutes in the Jigsaw Listening 3 condition. All participants were informed beforehand about their listening procedures. While listening, they were encouraged to take notes of listening content with a view to summarizing this content to their classmates in the sharing session. After the listening procedures, they all sat for the same text comprehension test that has been described above. After this test, one pair of learners were randomly selected from each jigsaw listening group for a follow-up interview. In this interview, the learners were required to describe in their L1 what activities they carried out during their jigsaw listening session, especially during the sharing task, and how these activities influenced their understanding and retention of the input content.

As all quantitative data were normally distributed, one-way ANOVA tests were used to compare the test scores across all learning conditions. Cohen's effect size $d$ was also computed to compare the listening outcomes between the jigsaw and the comparison conditions. Next, multiple regression analysis was implemented to gauge the predictive power of the nature of the learning conditions and the amount of time on task for the degree of text comprehension. In all tests above, a $p$ value of .05 was set as a threshold for the required significance level. With regards to the qualitative data, all participants' responses were first transcribed. Two experienced Vietnamese teachers of English were then invited to code instances of the four metacognitive processes that Vandergrift and Goh (2000) proposed in their model. There were only two differences in their coding results, which, however, were resolved after discussion.

\section{Findings}

\section{Quantitative data}

Table 1 presents the descriptive statistics for the scores that the participants in each group obtained on the text comprehension measure. Specifically, it includes the sample size $(n)$, the mean score $(M)$, the standard deviation $(S D)$, and the amount of time invested in each listening procedure (including the sharing session) (T).

Table 1: Text comprehension scores

\begin{tabular}{cccccc} 
& \multicolumn{2}{c}{ Comparison groups } & \multicolumn{3}{c}{ Treatment groups } \\
& $\begin{array}{c}\text { One-time } \\
\text { Listening }\end{array}$ & $\begin{array}{c}\text { Repeated } \\
\text { Listening }\end{array}$ & $\begin{array}{c}\text { Jigsaw } \\
\text { Listening 1 }\end{array}$ & $\begin{array}{c}\text { Jigsaw } \\
\text { Listening 2 }\end{array}$ & $\begin{array}{c}\text { Jigsaw } \\
\text { Listening 3 }\end{array}$ \\
\hline$n$ & 35 & 35 & 36 & 36 & 36 \\
$M$ & 4.91 & 6.03 & 5.56 & 7.11 & 7.95 \\
$S D$ & 1.10 & 0.82 & 0.94 & 0.86 & 0.96 \\
$T$ (in minute) & 6.16 & 12.32 & 8.16 & 11.16 & 14.32 \\
\hline
\end{tabular}

As can be seen from the above table, the learners in all jigsaw conditions obtained higher text comprehension scores than those in the One-time Listening condition. However, only the learners in the Jigsaw Listening 2 and the Jigsaw Listening 3 group outperformed those in the Repeated Listening group.
Table 2 provides Cohen's effect sizes $d$ indicating the differences in the listening outcomes between the jigsaw and the comparison groups. 
Table 2: Cohen's effect size $d$ for the difference in the listening outcome across all groups

Jigsaw Listening 1

Jigsaw Listening 2

Jigsaw Listening 2

\begin{tabular}{lccc}
\hline One-time Listening & .64 & 2.23 & 2.94 \\
Repeated Listening & -.53 & 1.29 & 2.15 \\
\hline \multicolumn{4}{c}{$.20-.50:$ small; $.51-.80:$ medium; .81 and above: large }
\end{tabular}

It is clear from the above table that the difference in the listening outcomes between the One-time Listening group and the Jigsaw Listening 1 group was medium. However, the difference between the One-time Listening condition on the one hand and the Jigsaw Listening 2 and the Jigsaw Listening 3 condition was large. This also holds true for the differences in the listening outcomes between the Repeated Listening group and the three Jigsaw Listening groups.

To further examine the difference in the test scores across all learning conditions, a oneway ANOVA test for independent samples was carried out. The result showed that there was at least one group whose test scores significantly differed from those achieved by another group: $F(4,173)=59.94(p<.000)$. Tukey post hoc tests were subsequently implemented for pairwise comparisons. The learners in the Jigsaw Listening 1 group scored significantly better on the text comprehension test than those in the One-time Listening group $(p<.05)$. So did those in the Jigsaw Listening 2 and the Jigsaw Listening 3 group $(p<.01)$. The test scores made by the Jigsaw Listening 2 and the Jigsaw Listening 3 group also significantly surpassed those obtained by the Repeated Listening group $(p<.01)$. There was, however, no significant difference in the test scores between the Repeated Listening and the Jigsaw Listening 1 condition $(p=.21)$. It should also be noted that the Repeated Listening condition fared better than the One-time Listening condition $(p<.01)$. Ranking the effects of the learning conditions on text comprehension yields, in ascending order, One-time Listening $<$ Repeated Listening $\approx$ Jigsaw Listening $1<$ Jigsaw Listening $2<$ Jigsaw Listening 3.

The above differences might also be attributed to the differing amounts of time

that learners in each group needed to complete their assigned procedure. To examine whether it was the nature of the learning conditions or the amount of time on task that accounted for most of the difference, I incorporated these two variables into a regression model. This model explained $56.19 \%$ of the variance in the test scores: $F(2,175)=114.51(p<.000)$. The nature of the learning conditions and the amount of time on task were both found to predict the test scores with Beta $=.75, t$ $=6.62(p<.000)$ and Beta $=.66, t=12.00$ $(p<.000)$, respectively. To be more specific, the former explained $45.54 \%$ of the variance in the test scores $(F(1,176)=149, p<.000)$, while the latter accounted for merely $21 \%$ of such variance $(F(1,176)=49.97, p<.000)$.

Taken together, all jigsaw listening conditions indeed created a positive effect on L2 listening comprehension as expected. It should, however, be noted that this effect was also moderated by the amount of time on task.

\section{Qualitative data}

According to the learners who were randomly selected for follow-up interviews, the jigsaw listening activities prompted them to carry out different metacognitive processes and it was these processes that helped them to obtain the listening outcomes above. In what follows, I shall report these processes in more detail.

First, most of the interviewees, regardless of their assigned jigsaw listening tasks, shared the same view that as they were informed beforehand about the follow-up sharing session, they became more engaged with the listening process (JS11, JS21, JS32) as well as the note-taking process (JS11, JS12, JS21, JS31, JS32), which both, in turn, fostered their comprehension and retention of the input content (JS11, JS12, JS21, JS32). 
They also added that these sharing sessions provided them with a valuable opportunity to reprocess perceived information in their notes, which thus enhanced their text comprehension (JS11, JS12, JS21, JS22, JS31, JS32). JS12, for example, described this benefit in the following analogy: "This summary activity is just like a way for me to step back to reevaluate what I have heard and to see the whole picture of the given message. In this way, I can improve my understanding of the listening content considerably". Some further elaborated such a re-evaluation with a list of different cognitive activities that they carried out for that purpose like differentiating between main ideas and specific information (JS11, JS12, JS22, JS32), fastening the focus on main ideas only (JS11, JS12, JS21) or reorganizing the main ideas in a logical sequence (JS11, JS12, JS21, JS 22, JS31).

The learners who were given the opportunity to revisit the material that they had already listened to once before (i.e., the learners in the Jigsaw Listening 3 condition) added many other merits of the sharing session (JS31, JS32). First, this sharing session helped them to identify deficiencies in their previous interpretation of the input content: "I have missed the information about different symbols that the writer employed in his novel" (JG31) or "In the first listening, as I lost my concentration in the final part of the recording I did not understand much about the connections between some key concepts that were mentioned in that novel" (JS32). Interestingly, these learners both used those deficiencies to set the goals or foci for their second listening: "Such a gap directed my attention to relevant information in my second listening and then I noted it down here in red ink [referring to her notes]" (JS31) or "I hesitated here [there was a long pause in the recording of her sharing session] as I missed the information about how the concepts were connected. In the second time, I understood more about this connection. Actually, the writer aimed to demonstrate how one concept in our daily lives influenced another, like how the surrounding environment influenced our mental and physical well-beings, for example" (JS32). The learners even used what they had summarized as an advance organizer to facilitate their second listening: "I used the main ideas in my summary as a checklist to confirm my previous understanding of the input content, add further information, or correct my misunderstanding" (JS31) or "I used the main ideas in my summary as signposts to aid my text comprehension in my second listening" (JS32).

Those students who received a summary of the input content before they actually listened to that content themselves (i.e., the learners in the Jigsaw Listening 2 and the Jigsaw Listening 3 condition) used the summary strategically to foster their listening process. JS12, JS22 and JS32, for instance, reported that the summary gave them the topic of the upcoming content, which therefore helped them to activate their top-down processing: "Through her sharing, I know the topic of the upcoming content" (JS32) or "This sharing session is very helpful for my actual listening as I know the topic and thus I can predict its likely content" (JS22). JS31 and JS33 used the sequence of information given in such a summary as an advance organizer to guide their actual listening: "Through her summary, I can catch some key words which I use as signposts to facilitate my actual listening" (JS31) or "I use the key ideas in her summary to predict what is coming next in my actual listening" (JS32). Interestingly, based on the given information in such a summary, these learners established different hypotheses about the upcoming content. Therefore, during their actual listening session, they merely needed to confirm what had been said (JS21, JS22), add further detailed information to the key point in the summary (JS21, JS32), reject this information when it was not mentioned or incorrect (JS21, JS22, JS31). Thanks to these benefits, they found their actual listening much easier (JS21, JS22, JS31) and thus they 
enjoyed listening rather than made effort to take in the input content (JS21, JS32).

Table 3 below summarizes different metacognitive strategies, together with specific mental processes, which the learners above carried out in order to complete their assigned jigsaw listening task.

Table 3: Metacognitive strategies and mental processes used across the jigsaw listening tasks

\begin{tabular}{|c|c|c|c|c|}
\hline & $\begin{array}{l}\text { Jigsaw } \\
\text { Listening } \\
\quad 1\end{array}$ & $\begin{array}{l}\text { Jigsaw } \\
\text { Listening } \\
\quad 2\end{array}$ & $\begin{array}{l}\text { Jigsaw } \\
\text { Listening } \\
\quad 3\end{array}$ & Specific mental processes \\
\hline Planning & & $\sqrt{ }$ & $\sqrt{ }$ & $\begin{array}{l}\text { - Use the topic, key words and/or main ideas } \\
\text { from the provided summary to activate top-down } \\
\text { processing }\end{array}$ \\
\hline Monitoring & & $\sqrt{ }$ & $\sqrt{ }$ & $\begin{array}{l}\text { - Use the key words in such a summary as } \\
\text { signposts to walk them through the input content } \\
\text { in their actual listening; } \\
\text { - Use the ideas provided in that summary to form } \\
\text { hypotheses about listening content; } \\
\text { - Accept, reject or modify these hypotheses using } \\
\text { evidence from their actual listening process }\end{array}$ \\
\hline $\begin{array}{l}\text { Problem- } \\
\text { solving }\end{array}$ & & & $\sqrt{ }$ & $\begin{array}{l}\text { - Use the gaps in the previous interpretation } \\
\text { of input content as a basis to draw attention to } \\
\text { relevant information in the second listening; } \\
\text { - Fill these gaps }\end{array}$ \\
\hline Evaluating & $\sqrt{ }$ & $\sqrt{ }$ & $\sqrt{ }$ & $\begin{array}{l}\text { - Reprocess perceived information in the notes at } \\
\text { a deeper level; } \\
\text { - Differentiate between main ideas and specific } \\
\text { information; } \\
\text { - Fasten their focus on main ideas only; } \\
\text { - Reorganize these main ideas in a coherent } \\
\text { structure; } \\
\text { - Identify deficiencies in the previous interpretation } \\
\text { of input content }\end{array}$ \\
\hline
\end{tabular}

\section{Discussion and pedagogical implications}

\section{Discussion}

Regarding the first research question, the learners in all Jigsaw Listening groups outperformed those in the One-time listening group on the post-treatment listening test. It was interesting to find out that the learners who listened to either the first or the second half of the input text and then shared the content with those who did not listen to the same half (i.e., the Jigsaw Listening 1 condition) obtained significantly better text comprehension than those who listened to the entire input text, but merely once (i.e., the One-time Listening condition). One plausible explanation for this finding is that the announcement of the follow-up sharing session in the Jigsaw Listening 1 condition might have prompted learners to be more engaged with their input processing, which could have fostered their text comprehension better than the mere exposure to the listening passage. In fact, most of the interviewees in the present study supported this stance. This finding therefore echoes what Stahl and Clark (1987) found about the positive effects of participatory expectation in classroom discussion on the quality of input processing and new concept acquisition in the context of L1 reading.

Nevertheless, the learners in the Jigsaw Listening 1 condition did not fare better on 
the same text comprehension measure than those who listened to the whole input text twice (i.e., the Repeated Listening condition). This finding was, however, not unexpected. In fact, the learners in the Jigsaw Listening 1 condition were exposed to only half of the input material. Whether they could cultivate the understanding of the whole input content heavily depended on the quality of the summary that their classmate gave them. Meanwhile, those in the Repeated Listening group had the opportunity to listen to the same input text twice. Previous research has consistently showed that having L2 learners listen to the same input text twice renders a better listening outcome than having them listen to the same text once (Nguyen \& Boers, 2019; Chang \& Read, 2006; Saika, 2009). These studies all suggest that the reassurance that listening input material will be played more than once helps learners reduce their listening anxiety, which, in turn, makes them more mentally engaged with the listening process. In addition, as a way of catering for the limited capacity of human working memory (Robinson, 2003), this type of listening gives L2 learners another listening time (which also entails more total time on task) to verify their previous interpretation of listening content and add information they have missed during their previous listening (Chang \& Read, 2006). Put differently, repeated listening benefits L2 listeners both affectively and cognitively.

The learners who listened to either the first or the second half of the listening passage, reported the listening content to a classmate, and then moved on with the other half (i.e., the Jigsaw Listening 2 condition) scored better than those who listened to the entire passage once (i.e., the One-time Listening condition) and better also than those who listened to the same input text twice (i.e., the Repeated Listening condition). The better listening outcome obtained by the Jigsaw Listening 2 group might be attributed to the positive effects of the sharing session in their assigned listening procedure. As already discussed above, on the part of the summary givers, the announcement of the follow-up sharing session might have made them more engaged with their input processing, which, therefore, could have enhanced their text comprehension. In addition, in order to sum up the listening content to their classmates, the learners in this learning condition might also have reprocessed information in their notes. It is generally believed that the more a set of information is processed, the better it tends to be understood and memorized (Wittrock, 2010). In fact, the learners who were involved in the follow-up interviews reported that the sharing session prompted them to take a closer look at their notes, browse such notes for the main ideas of the listening passage, and then organize these main ideas in a coherent structure. Through these processes, they also identified what they missed in their first listening. In their opinions, it was those processes that fostered their text comprehension. This finding appears to support Wittrock's Model of Generative Teaching of Comprehension (2010) in at least two interrelated aspects. First, the summary activity in the present study prompted L2 listeners to generate mental links between different ideas in the given input text. Second, such a generation indeed facilitated their listening outcome. Thus, the model above not only holds true for L1/L2 reading (as found in previous research) but for L2 listening as well.

On the part of the summary receivers, they may have used the information provided in such a summary as an advance organizer of the upcoming listening content. This advance organizer could have allowed them to save a considerable amount of mental resources, which, in turn, may have helped them to travel back and forth between the top-down and the bottom-up processes. In other words, having a summary of input content as an advance organizer before actual listening could have enabled those learners to make use of both topdown and bottom-up processes for the purpose of text comprehension. Thus, this finding is 
still in keeping with Ausubel's (1978) claim about the merits of providing L2 listeners with an advance organizer of upcoming content for their text comprehension. It also underscores the importance of both top-down and bottomup processing in L2 listening comprehension.

Those who listened to either the first or the second half of the input content, shared that content to a classmate who had not listened to that content yet, and then listened to the whole listening passage (i.e., the Jigsaw Listening 3 condition) obtained significantly higher test scores than their counterparts in any other groups (i.e., the One-time Listening, the Repeated Listening, the Jigsaw Listening 1 and the Jigsaw Listening 2 condition). Apart from all aforementioned benefits, the learners in the Jigsaw Listening 3 condition were also provided with the opportunity to revisit the material that they had already listened to once before. Such a revisit, as already discussed above, might have helped the learners in this condition to reduce their listening anxiety as well as recollect the information that they already missed in their first listening.

In answer to the second research question, the effects on text comprehension of the three jigsaw listening tasks were indeed moderated by the amount of time on task. To be more specific, the more time the learners invested in a listening procedure, the better their listening outcome tended to be. It should, however, be noted that the nature of the learning conditions was a better predictor of the listening outcomes than the amount of time on task, with Beta of .75 and .66 , respectively. In addition, the learners in the Jigsaw Listening 2 condition spent only 11.16 minutes on their listening procedure, while those in the Repeated Listening condition needed 12.32 minutes to complete their listening task. Nevertheless, the former were found to obtain significantly better text comprehension than the latter. Therefore, it might be more rational to imply that it is the quality of information processing (brought about by the meaning-focused input and/or meaning-focused output tasks inserted in each listening condition) rather than the amount of time invested in that condition that matters.

With regards to the final research question, Table 3 above indicates that in order to complete their assigned jigsaw listening task, the learners in this study employed at least one out of the four metacognitive strategies that Vandergrift and Goh (2012) presented in their model. It is also interesting to note that the more metacognitive strategies that the learners employed for a particular jigsaw listening condition, the better listening outcome this condition tended to bring about. This finding first appears to be consistent with what Gu et al. (2009) and Vandergrift (2003) found about the positive effects of the metacognitive strategies on L2 listening outcome. However, what is new in this finding is the positive correlation between the number of metacognitive strategies employed and the degree of text comprehension.

\section{Pedagogical implications}

The present study shows that jigsaw listening indeed offers many benefits other than a mere platform to promote learner autonomy and cooperative learning. Therefore, the incorporation of this listening procedure into classroom practice should also focus on these benefits as well as how to make full use of these benefits for the purpose of L2 listening comprehension and metacognitive strategies development.

First, in the pre-listening stage, instructors of L2 listening courses need to inform learners about the presence of the follow-up sharing session in jigsaw listening. Such an announcement was found to prompt learners to be more engaged with their listening process, which, in turn, enhanced their listening outcome.

Second, as the three jigsaw listening activities in this experiment were found to have differing effects on L2 listening comprehension, we need to pay more attention 
to the activity that proves to be the most conducive to learning, i.e., having learners listen to either the first or the second half of an input text, share the content with a classmate who has not been exposed to the same content yet, and then listen to the whole listening passage. This listening procedure was found to provide learners with the opportunity to plan for, monitor their listening process, identify their listening problems and find suitable solutions for those problems as well as evaluate their listening outcome - the four metacognitive processes that are often found to foster L2 listening comprehension.

In this study, it was the learners themselves that initiated the use of metacognitive strategies to facilitate their listening process (presumably because they had learnt about those strategies already). In other teaching contexts, however, it might also be a good idea to instruct learners on those strategies beforehand. Such instruction is expected to enable learners to use the strategies more systematically and therefore optimize the benefits that those strategies might bring about for text comprehension. Next, this instruction also needs to provide learners with the opportunity to activate and exercise the specific mental processes presented in Table 3 above as these processes were also found to foster L2 listening comprehension.

Finally, the present study suggests that it is the depth of information processing over and above the amount of time on task that benefits L2 listening and that listeningbased output tasks, while requiring a certain time investment, are useful in this regard. Therefore, integration of such a text-based output task into listening-based lessons is highly recommended.

\section{Limitations and conclusion}

This study is limited in three different aspects. First, it did not examine the quality of the summaries that the learners gave their classmates. It might be interesting to investigate whether the quality of these summaries affected the listening outcome of the summary receivers. In addition, the followup interviews did not include all learners from all jigsaw listening groups. Although the interviewees were randomly selected in this case, their ideas need not be representative of those of all research participants. Finally, as the input material was taken from an official IELTS test in the past, some participants might have encountered this or similar material prior to their involvement in this experiment.

Despite these shortcomings, it is still clear from the above report that jigsaw listening fosters L2 listening comprehension. To be more precise, this listening technique prompts learners to activate and exercise such metacognitive strategies as planning, monitoring, problem-solving and evaluating, which, in turn, help them enhance their understanding and retention of listening content. These findings are in keeping with such well-established theories and/or models in the field of L2 listening instruction as Vandergrift and Goh's Model of Metacognitive Listening (2012), Wittrock's Model of Generative Teaching of Comprehension (2010), and Ausubel's Advance Organizer of Upcoming Listening Content (1978). In order to make full use of jigsaw listening for the purpose of L2 listening ability development, instructors may need to inform their learners beforehand about the presence of the follow-up sharing session with a view to getting them more engaged with their listening process, provide the learners with effective training on metacognitive strategies for optimizing their listening outcome, and expose the learners to such a sequence of meaning-focused input and output activities that is conducive to learning as in the case of the Jigsaw Listening 3 in the present study.

\section{References}

Ausubel, D.P. (1978). In defence of advance organizers: A reply to the critics. Review of Educational Research, 48(2): 251-257. 
Chang, A. and Read, J. (2006). The effects of listening support on the listening performance of EFL learners. TESOL Quarterly, 40(2): 375-397.

Chofifah, L. and Kumalarini, D.T. (2013). The implementation of jigsaw listening to increase the listening comprehension of the tenth grade students Sman 1 Porong. EJournal Unesa, 1(1): 01-07.

Geddes, M. and Sturtridge, G. (1978). Jigsaw listening: Integrating listening and oral skills. Englisch, 13(3): 90-93.

Gu, P.Y., Hu, G.W. and Zhang, L.J. (2009). Listening strategies of Singaporean primary pupils. In: Silver, R.E., Goh, C.C.M. and Alsagoff, L. (eds). Language Learning in New English Contexts: Studies of Acquisition and Development. London: Continuum, pp. 55-74.

Harlim, L. (1999). Cooperative learning using jigsaw as a technique in teaching listening comprehension. BA Thesis, Widya Mandala Catholic University, Indonesia.

Herron, C., York, H., Cole, S.P. and Linden, P. (1998). A comparison study of student retention of foreign language video: Declarative versus interrogative advance organizer. The Modern Language Journal, 82(2): 237-247.

Jafari, K. and Hashim, F. (2012). The effects of using advance organizers on improving EFL learners' listening comprehension: A mixed method study. System, 40(2): 270-281.

Kazemi, M. (2012). Exploring the Iranian EFL learners' reading performance: The effect of teaching method. International Journal of Applied Linguistics and English Literature, 1(6):170-184.

Mauludi, M. (2011). The effectiveness of jigsaw to improve students' reading narrative text ability. Master Thesis, Walisongo State Institute for Islamic Studies, Kendal.

Nguyen, C.D. and Boers, F. (2019). The effect of content retelling on vocabulary uptake from a TED talk. TESOL Quarterly, 53(1): 5-29.

Prom, D. (2012). The effect of jigsaw II technique on reading comprehension of Mattayom Suksa
1 students. Master Thesis, Srinakharinwirot University, Thailand.

Robinson, P. (2003). Attention and memory during SLA. In: Doughty, C.J. and Long, M.H. (eds). The Handbook of Second Language Acquisition. New York: Blackwell Publishing, pp.631-678.

Sakai, H. (2009). Effect of repetition of exposure and proficiency level in L2 listening tests. TESOL Quarterly, 43(2): 360-372.

Schmitt, N., Schmitt, D. and Clapham, C. (2001). Developing and exploring the behaviour of two new versions of the Vocabulary Levels Test. Language Testing, 18(1): 55-88.

Stahl, S. and Clark, H. (1987). The effects of participatory expectations in classroom discussion on the learning of science vocabulary. American Educational Research Journal, 24(4): 541-555.

Tuanany, N. and Bharati, D.A.L. (2017). The effectiveness of jigsaw listening and problemsolving techniques to teach listening comprehension using authentic materials with different levels of anxiety: A case at the tenth graders of Swan 11 Kota Ambon in the academic year 2015-2016. English Education Journal, 27(1): 42-46.

van Zeeland, H. (2013). Vocabulary and listening. In: Chapelle, C.A. (ed). The Encyclopaedia of Applied Linguistics. Australia: Wiley-Blackwell, pp.01-06.

Vandergrift, L. (2003). Orchestrating strategy use: toward a model of the skilled second language listener. Language Learning, 53(3): 463-496.

Vandergrift, L. and Goh, C.C. (2012). Teaching and Learning Second Language Listening: Metacognition in Action. Oxford: Taylor and Francis Group.

Wittrock, M.C. (2010). Learning as a generative process. Educational Psychologists, 45(1): 40-45.

\section{Appendix}

Appendix A: $\quad \underline{\text { https://takeielts.britishcouncil.org/ }}$ sites/default/files/2018-01/Listening_practice_ questions_121012.pdf. 


\section{ĐO HIỆU QUẢ NGHE HIỂU CỦA BA HOẠT ĐộNG JIGSAW ĐIỂN HİNH}

Nguyễn Chí Đức, Phạm Xuân Thọ

Trường Đại học Ngoại ngũu, Đại học Quốc gia Hà Nội

Phạm Văn Đồng, Cầu Giấy, Hà Nội, Việt Nam

Tóm tắt: Nghiên cứu này so sánh hiệu quả của ba tiến trình nghe hiểu theo hình thức jigsaw. Ở tiến trình thứ nhất, người học sẽ được chia làm hai nhóm, mỗi nhóm nghe nửa đầu hoặc nửa sau của một văn bản, sau đó bắt cặp và kể lại cho nhau nội dung vừa được nghe (Jigsaw 1). Ở tiến trình thứ hai và thứ ba, người học thực hiện tương tự các bước trên, tuy nhiên sau đó họ được nghe lại nửa văn bản mà bạn họ vừa kể (Jigsaw 2) hoặc toàn bộ văn bản (Jigsaw 3). Mức độ nghe hiểu của họ được so với hai nhóm đối chứng, những người được nghe cùng văn bản nêu trên một lần (đối chứng 1) hoặc hai lần (đối chứng 2). Kết quả chỉ ra rằng các nhóm Jigsaw đều có kết quả nghe hiểu tốt hơn so với nhóm đối chứng 1 . Nhóm Jigsaw 2 và 3 nghe hiểu tốt hơn so với nhóm đối chứng 2 . Kết quả phỏng vấn 03 cặp học viên được lựa chọn ngẫu nhiên từ ba nhóm Jigsaw cho thấy các học viên này sử dụng rất nhiều chiến lược nghe hiểu bậc cao trong các tiến trình nghe hiểu kể trên và chính các chiến lược này đã giúp họ nghe hiểu tốt hơn. Những phát hiện này có ý nghĩa sư phạm hữu ích đối với cả giáo viên dạy kỹ năng nghe và người thiết kế môn học.

Tù khoá: hoạt động nghe hiểu theo hình thức jigsaw, nghe hiểu văn bản, chiến lược nghe hiểu bậc cao, chuẩn bị về nội dung và tổ chức văn bản trước khi nghe 